\title{
Editorial
}

This volume is a new-look issue of the Journal of NELTA. With a view to meeting the growing interest and demands of NELTA members, the newly constituted editorial board of NELTA, in consultation with NELTA leadership, has introduced some changes in the presentation of the Journal. The first and foremost change is the way in which the contents of the Journal have been presented. They have been organised in five different sections. The first section is comprised of feature articles. There are ten articles in this section authored by highly experienced teachers and teacher educators from home and abroad. These articles broadly address four major themes of English language teaching: teachers and teacher education, teaching methodology, e-learning and media use, and teaching and learning resources. The findings and implications reported in these articles are valuable and worth exploring.

Second, a sizeable number of NELTA members look on a regular basis for ideas and teaching tips that help them in their day-to-day teaching. More than theoretical issues, they are interested in ideas that they can put in practice without having to do much preparation. In order to help such teachers, a new section, "Practical Pedagogic Ideas," has been introduced. Ideas included in this section are ones developed by practicing teachers and/or teacher educators. We hope that readers get inspired to practice these ideas and contribute to the Journal by submitting their own practical teaching ideas.
In addition, the advent of ICT and Internet has made it possible for ELT practitioners from all over the world to connect. The technology has changed the way we interact and share our ideas with individuals and organisations located in every corner of the globe. Online media has enabled us to participate in any professional event no matter where it takes place. With a view to assisting NELTA members in this regard, the Journal has included a number of useful ELT related blogs for them to get involved in, as well as guidance of how to take part in conversations therein. With a similar objective, we have introduced the section "From the ELT World," which contains information on regional and international conferences. Many of these organisations may have sponsorships for emerging and early-career professionals. Interested NELTA members should contact the organisations directly. Finally, we have reintroduced the section "Book/material Reviews," which offers reviews of recent and relevant books/resources published in the field of ELT. One covert aim of this section is to encourage readers of this Journal to read and write their own reviews of books and other appropriate materials.

The Journal is also a platform for its readers to interact and respond to the materials published, and to share their views on them. To this effect, we introduce a new feature called "Journal of NELTA Forum," under which opinion article(s) will be published. Readers can write their informed response 
to the articles, a selection of which will be published in the next issue of the Journal.

With a view to facilitating the publication process, we have brought in a change in the Journal's editorial panel. The Journal now has an Advisory Board which consists of ELT professionals from around the world. The Advisory Board provides advice on matters related to the publication of materials. We are grateful to the members for agreeing to serve on the Board. The Editorial Board will continue to seek their support and advice on how to make the Journal better in the years ahead. The Reviewers Panel has also been expanded with more domestic and international experts to ensure rigorous and quality review of the materials received. We welcome our advisors and reviewers. Similarly, in order to make the editorial process more transparent and accountable, the members of the editorial board are also now section editors. In addition to the feature articles and conference proceedings, they are also responsible for an allocated section for which they receive, review and edit submissions.
We hope the changes introduced in the editorial process help to make the Journal a complete and quality journal, a journal its readers enjoy and are encouraged to be a part of. We also hope that its authors and reviewers feel pride in associating with it. We take this opportunity to thank the authors for submitting their valuable work and for maintaining patience during the long review process. We thank our reviewers for taking time out of their busy schedule to review the submissions. Their work helps us improve the quality of the Journal. We also thank Deborah Silver, for fixing the language anomalies, our guest editor Mr. Z. N. Patil for his guidance and Dr Motikala Subba Dewan, president of NELTA, for her support.

Happy reading!

\section{Board of Editorial}

